\title{
Implementasi Computational Thinking Melalui Pemrograman Visual dengan Kolaborasi Mata Pelajaran pada Siswa Menengah Atas
}

\author{
Maresha Caroline Wijanto ${ }^{\# 1}$, Robby Tan ${ }^{\# 2}$, Sendy Ferdian Sujadi ${ }^{* 3}$, Billy Susanto Panca ${ }^{\# 4}$, Hapnes Toba ${ }^{+5}$, Diana \\ Trivena Yulianti ${ }^{* 6}$, Setia Budi ${ }^{+7}$, Sulaeman Santoso ${ }^{\# 8}$, Andreas Widjaja ${ }^{+9}$, Rossevine Artha Nathasya ${ }^{\# 10}$, Gisela \\ Kurniawati $^{\# 11}$, Oscar Karnalim ${ }^{\# 12}$ \\ \# Teknik Informatika, Universitas Kristen Maranatha
}

Jl. Prof. drg. Surya Sumantri, M.P.H. no. 65, Bandung 40164, Jawa Barat, Indonesia

${ }^{1}$ maresha.cw@it.maranatha.edu

2robby.tan@it.maranatha.edu

${ }^{4}$ billy.sp@it.maranatha.edu

${ }^{8}$ sulaeman.santoso@it.maranatha.edu

${ }^{10}$ rossevine.an@it.maranatha.edu

${ }^{11}$ gisela.kurniawati@it.maranatha.edu

${ }^{12}$ oscar.karnalim@it.maranatha.edu

* Sistem Informasi, Universitas Kristen Maranatha

Jl. Prof. drg. Surya Sumantri, M.P.H. no. 65, Bandung 40164, Jawa Barat, Indonesia

${ }^{3}$ sendy.fs@it.maranatha.edu

6diana.trivena@it.maranatha.edu

+ Magister Ilmu Komputer, Universitas Kristen Maranatha

Jl. Prof. drg. Surya Sumantri, M.P.H. no. 65, Bandung 40164, Jawa Barat, Indonesia

${ }^{5}$ hapnestoba@it.maranatha.edu

${ }^{7}$ setia.budi@it.maranatha.edu

9andreas.widjaja@it.maranatha.edu

\begin{abstract}
Abstrak-Dalam kurikulum pendidikan K-12 Indonesia terbaru (2013), mata pelajaran Informatika tidak lagi menjadi mata pelajaran wajib, melainkan menjadi mata pelajaran pilihan pada peminatan akademik. Padahal di era digital ini, pemahaman dan implementasi praktis dari berpikir komputasi sangat diperlukan. Fakultas Teknologi Informasi Universitas Kristen Maranatha mendukung penyebaran kemampuan berpikir komputasi untuk sekolah dasar dan menengah pertama maupun atas. Pengabdian kepada masyarakat kali ini mengajarkan penerapan kemampuan berpikir komputasi melalui pemrograman visual, yaitu Scratch dan CodeCombat, untuk sekolah menengah atas binaan. Kegiatan yang dilakukan dimulai dari persiapan, pemberian materi, dan sesi kreativitas siswa. Materi dikolaborasikan dengan mata pelajaran lainnya, yaitu Matematika dan Kesenian. Para siswa diharapkan untuk mengerjakan proyek akhir dan didorong untuk mengandung unsur kebudayaan lokal, yaitu Sunda atau Jawa Barat.
\end{abstract}

Dikarenakan masih dalam kondisi pandemi, maka kegiatan ini dilakukan secara online. Siswa mengikuti kegiatan ini dengan baik dan dari hasil survey yang ada, siswa merasa materi ini menyenangkan dan dapat berguna untuk kegiatan sekolah mereka.

Kata kunci-informatika, berpikir komputasi, pemrograman visual, kolaborasi, kreativitas.

Abstract-In the most recent Indonesian K-12 education curriculum (2013), Informatics is no longer mandatory; it becomes an optional subject for a particular academic interest. Whereas in this digital era, understanding and being able to implement computational thinking is a must. Faculty of Information Technology Maranatha Christian University promotes the influence of computational thinking skills for primary and secondary schools. This community service activity educates high school students about the application of 
computational thinking skills through visual programming via Scratch and CodeCombat. The activity consists of three sessions: preparation, lecture, and student creativity. The materials were integrated with existing school materials: Mathematics and Arts. Participating students were expected to submit a final project that, if possible, is relevant to local culture, such as those of Sundanese or West Java. Due to the pandemic, this community service activity was held online. Students participated well in this activity and according to a survey distributed at the end of the activity, students felt this material was fun and could be useful for their school activities.

Keywords-informatics, computational thinking, visual programming, collaboration, creativity.

\section{Pendahuluan}

Kurikulum 2013 mulai diterapkan sejak tahun ajaran 2013/2014. Hanya saja mata pelajaran (mapel) Teknologi Informasi dan Komunikasi (TIK) sempat dihapuskan di Kurikulum 2013 ini [1]. Lalu pada tahun 2019, terjadi perubahan pada kurikulum 2013 dimana mapel TIK menjadi mapel Informatika dan sifatnya menjadi tidak wajib. Mapel Informatika diberikan melalui mapel pilihan pada kelompok B (kelompok mapel yang dikembangkan oleh Pemerintah Pusat dan dapat dilengkapi dengan muatan/konten lokal) untuk tingkat SMP/MTs dan mapel pilihan pada kelompok C (kelompok mapel yang dikembangkan Pemerintah Pusat dan merupakan mapel peminatan akademik atau pilihan) untuk tingkat SMA/MA [2].

Kurikulum 2013 memanfaatkan TIK sebagai alat pembelajaran (ICT for learning) yang mengintegrasikan semua mapel. Hal ini juga untuk mempersiapkan bangsa Indonesia masuk Revolusi Industri 4.0 yang menghadirkan sistem cyber-physical. Industri dan kehidupan sehari-hari mulai memanfaatkan komunikasi manusia dan mesin/komputer, contohnya robot pintar, penggunaan Internet of Things, bahkan rekayasa genetika [2]. Manusia sendiri telah memasuki era Society 5.0, dimana masyarakat hidup di dunia nyata dan juga dunia digital [3].

Dengan dekatnya dunia nyata dan dunia digital, sistem pendidikan Indonesia juga perlu sejak dini membentuk kesiapan masyarakat Indonesia. Untuk mempersiapkannya, siswa harus memiliki pemahaman yang benar tentang prinsip dan penerapan dari Informatika [4]. Informatika disini berfokus pada Computational Thinking (CT), dimana dengan kemampuan CT ini siswa dapat memanfaatkan/mendesain sistem komputer dengan baik dan mampu memformulasikan masalah untuk memahami isu-isu secara rasional sehingga dapat memberikan solusi persoalan (problem solving) [5]. CT juga bukan hanya penting untuk pengembangan aplikasi komputer, tetapi juga dapat mendukung pemecahan masalah (problem solving) untuk bidang ilmu lainnya, seperti matematika, sains, dan humaniora [6]. Banyak negara maju juga sudah mengimplementasikan standar dan kurikulum Informatika, seperti yang dirilis oleh Association for Computing Machinery (ACM), Computer Science Teacher Association (CSTA), dan lembaga nirlaba (sebagai contoh: code.org) [2].

Informatika adalah ilmu formal yang abstrak, sehingga memerlukan pendekatan yang khusus, antara lain Problembased Learning, Project-based Learning, dan Inquirybased Learning [2]. Untuk mempercepat peningkatan mutu pendidikan, Kementerian Pendidikan, Kebudayaan, Riset, dan Teknologi (Kemendikbud) bekerja sama dengan pemerintah daerah meluncurkan Sekolah Penggerak (SP). Kurikulum Informatika wajib diterapkan pada SP. Nantinya SP dapat menjadi klinik bagi sekolah sekitarnya dan mendampingi dalam perubahan pembelajaran. Karena wilayah Indonesia yang sangat luas, transformasi SP ini juga membutuhkan waktu dan juga kemauan dari sekolah [7].

Fakultas Teknologi Informasi Universitas Kristen Maranatha (FIT Maranatha) juga terus berupaya membantu sekolah agar siap dalam menerapkan Informatika, yaitu dengan aktif melakukan pengabdian kepada masyarakat ke sekolah dan aktif sebagai Biro Bebras dalam rangka edukasi CT [8], [9]. Dalam masa pandemi COVID-19 juga FIT Maranatha tetap aktif dalam membagikan ilmu Informatika secara daring. Walaupun pembelajaran daring memiliki tantangannya tersendiri apalagi secara mendadak terjadi peralihan [10], [11], FIT Maranatha tetap berupaya untuk mengadakan pengabdian kepada masyarakat secara daring.

Edukasi CT perlu diberikan dalam bentuk yang menarik dan menyenangkan agar siswa menjadi tertarik dan ingin terus mempelajarinya [5]. Pengabdian kepada masyarakat yang dilakukan rutin oleh FIT Maranatha salah satunya adalah pelatihan pemrograman visual berbasis blok. Kemampuan CT dapat dikembangkan melalui pemrograman visual berbasis blok, salah satu contohnya Scratch [12]. Pemrograman blok ini banyak digunakan karena membuat siswa fokus pada logika dan konsep umum pemrograman dan memiliki visualisasi yang baik [13] Pelatihan CT dengan pemrograman blok dari FIT Maranatha salah satunya rutin dilakukan di SMA St. Angela Bandung. Pada tahun 2020, untuk pertama kalinya pelatihan dilakukan secara daring.

\section{METODE PELAKSANAAN}

FIT Maranatha sudah melakukan kegiatan pengabdian kepada masyarakat di SMA St. Angela Bandung sejak 2015 dan rutin dilakukan setiap tahunnya. Dikarenakan kondisi pandemi Covid-19, maka pelaksanaan pengabdian kepada masyarakat dilakukan secara daring melalui aplikasi Microsoft Teams sekolah. Dengan peralihan pembelajaran daring secara mendadak dan belum siapnya sarana 
prasarana siswa dalam menjalankan pembelajaran daring [10], [11], maka diperlukan aktivitas yang dapat membuat siswa tertarik dan senang ketika mempelajarinya.

Kemampuan problem solving dan computational thinking menjadi semakin diperlukan sejak dini untuk para siswa [5]. Hal ini dapat diasah dengan seringnya melakukan aktivitas berbasis CT, salah satunya dengan pemrograman blok. Dengan pemrograman blok, siswa diajak untuk mengasah logika dan terbiasa dengan konsep dasar pemrograman tanpa dipusingkan dengan syntax pemrograman. Contoh pemrograman blok yang cukup diminati adalah Scratch dan Blockly [13].

Scratch adalah sebuah hasil produk dari Lifelong Kindergarten Group dari MIT Media Lab. Scratch dibuat agar orang-orang dapat belajar untuk berpikir secara kreatif, sistematis, dan berkolaborasi dalam tim. Scratch dirancang untuk anak umur 8-16 tahun. Dalam pelaksanaannya, Scratch dilengkapi dengan visual programming di mana siswa dapat melakukan drag and drop pada setiap objek yang ada. Dengan Scratch, siswa dapat belajar strategi dalam menyelesaikan masalah, mendesain sebuah proyek, dan mengkomunikasikan ide [14]. Dalam penelitian Zhang dan Nouri, fitur yang disediakan pada Scratch mencakup kemampuan CT yang dapat mendukung siswa untuk terus mengembangkan kemampuan $\mathrm{CT}$ dan problem solving mereka [12].

Selain dengan pemrograman blok, ada juga cara lain untuk mempelajari pemrograman, yaitu typed-code programming yang dikenalkan melalui CodeCombat. Sedikit berbeda dengan pemrograman blok, CodeCombat ini menerapkan pembelajaran berbasis game atau gamebased learning dimana siswa harus mengetik kode program untuk menyelesaikan level permainan yang ada. Bahasa pemrograman yang dapat dipelajari adalah Python dan JavaScript [15]. Kode program yang harus diketik siswa sesuai dengan bahasa pemrograman Python biasa, hal ini diasumsikan agar siswa dapat lebih terbiasa sedini mungkin dalam memahami konsep dasar pemrograman. Selain itu, siswa dapat bebas berkreasi karena solusi setiap level dapat dilakukan dengan berbagai cara asal mencapai tujuan yang ada [6].

Metode pengabdian yang dilakukan terbagi dalam tiga tahapan yaitu persiapan, pemberian materi, dan sesi kreativitas siswa. Tahapan persiapan yang dilakukan adalah adanya diskusi secara daring dengan pihak sekolah terkait topik pengabdian dan teknis pelaksanaan lainnya, khususnya karena pelaksanaan pengabdian dilakukan secara daring juga. Melalui tahap persiapan, diputuskan bahwa yang akan digunakan untuk pengabdian kali ini adalah Scracth untuk kelas $\mathrm{X}$ dan bahasa pemrograman Python dalam CodeCombat untuk kelas XI. Masing-masing topik ini dikolaborasikan dengan mata pelajaran lainnya, yaitu Scratch dengan mapel Kesenian dan CodeCombat dengan mapel Matematika. Selain itu, untuk tema proyek
Scratch disesuaikan dengan kearifan lokal yaitu kebudayaan Sunda/Jawa Barat. Selain itu, terdapat pelatihan materi untuk dosen dan mahasiswa yang terlibat.

Pendekatan yang dilakukan dalam penyampaian materi Scratch adalah project-based learning. Sedangkan untuk penyampaian materi CodeCombat menggunakan pendekatan problem-based learning. Awalnya pemberian materi diberikan dalam bentuk demonstrasi, dimana para fasilitator akan menunjukkan contoh-contoh sesuai panduan dan siswa juga dapat mencobanya bersama di perangkatnya masing-masing. Setelah itu, para siswa diberikan sejumlah waktu untuk mengerjakan proyek dimana proyek tersebut juga sudah disesuaikan dengan mapel kolaborasinya. Proyek ini menjadi sesi kreativitas siswa, karena siswa bebas menghasilkan produk asal sesuai dengan persyaratan proyek. Untuk proyek CodeCombat, kreativitas siswa dilihat dari bagaimana menyelesaikan masalah dalam tiap levelnya. Karena solusi dari setiap level bisa dilakukan dalam berbagai cara. Di akhir pengabdian, siswa diberi kesempatan untuk mempresentasikan hasil kreativitasnya masing-masing. Dan untuk siswa dengan hasil terbaik pilihan fasilitator akan diberikan hadiah khusus. Di akhir pelaksanaan juga terdapat evaluasi berupa survey terhadap aktivitas yang ada.

Fasilitator pengabdian ini merupakan para dosen dari Fakultas Teknologi Informasi Universitas Kristen Maranatha dan dibantu oleh mahasiswa dalam praktek pelaksanaannya.

\section{HASIL DAN PEMBAHASAN}

Sebelum pelaksanaan pengabdian berlangsung, semua fasilitator dan mahasiswa pendamping melakukan pelatihan dan persamaan persepsi. Pelatihan dilakukan secara daring untuk kedua materi yang akan dibagikan, yaitu Scratch dan CodeCombat. Pelaksanaan pelatihan ini dapat dilihat pada Gambar 1.

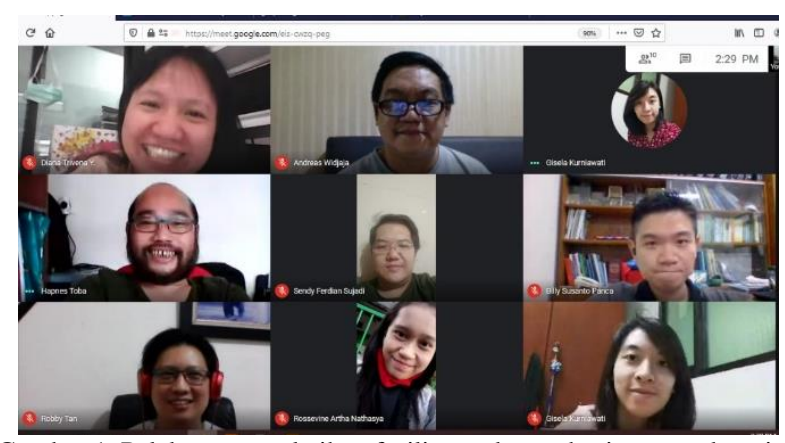

Gambar 1. Pelaksanaan pelatihan fasilitator dan mahasiswa pendamping

Pengabdian implementasi CT melalui pemrograman visual yang dilaksanakan di SMA St. Angela Bandung dilakukan pada bulan Agustus 2020. Pengabdian ini diikuti oleh 473 siswa yang berasal dari 16 kelas, terdiri dari 
masing-masing 8 kelas untuk kelas $\mathrm{X}$ dan kelas $\mathrm{XI}$. Pengabdian dipandu oleh 11 orang fasilitator yang merupakan dosen FIT Maranatha dan dibantu oleh 16 orang mahasiswa. Pembagian jumlah siswa dapat dilihat pada Tabel 1.

TABEL I PEMBAGIAN JUMLAH PESERTA PENGABDIAN

\begin{tabular}{|c|c|c|c|c|c|}
\hline \multicolumn{2}{|c|}{ Kelas } & Jumlah & $\mathbf{P}$ & $\mathbf{L}$ & Total \\
\hline \multirow{8}{*}{ X } & MIPA 1 & 28 & 16 & 12 & \multirow{8}{*}{226} \\
\hline & MIPA 2 & 28 & 14 & 14 & \\
\hline & MIPA 3 & 30 & 17 & 13 & \\
\hline & MIPA 4 & 28 & 16 & 12 & \\
\hline & MIPA 5 & 30 & 15 & 15 & \\
\hline & MIPA 6 & 26 & 15 & 11 & \\
\hline & IPS 1 & 29 & 20 & 9 & \\
\hline & IPS 2 & 27 & 22 & 5 & \\
\hline \multirow{8}{*}{ XI } & MIPA 1 & 30 & 15 & 15 & \multirow{8}{*}{247} \\
\hline & MIPA 2 & 30 & 16 & 14 & \\
\hline & MIPA 3 & 30 & 15 & 15 & \\
\hline & MIPA 4 & 30 & 17 & 13 & \\
\hline & MIPA 5 & 30 & 16 & 14 & \\
\hline & MIPA 6 & 30 & 17 & 13 & \\
\hline & IPS 1 & 34 & 20 & 14 & \\
\hline & IPS 2 & 33 & 19 & 14 & \\
\hline \multicolumn{2}{|c|}{ Total } & 473 & 270 & 203 & \\
\hline
\end{tabular}

Keterangan: $\mathrm{P}=$ Perempuan; $\mathrm{L}=$ Laki-laki

Pelaksanaan pengabdian dilakukan secara daring melalui aplikasi Microsoft Teams setiap kelas. Pelaksanaan untuk kelas XI dengan materi kolaborasi CodeCombat dan Matematika dilakukan pada hari pertama, setiap kelas dipandu oleh 1 orang fasilitator dan 2 orang mahasiswa pendamping. Pelaksanaan untuk kelas $\mathrm{X}$ dengan materi kolaborasi Scratch dan Kesenian dilakukan pada hari kedua dengan format pendampingan yang sama.

Pelaksanaan diawali dengan penjelasan dari fasilitator lalu siswa akan diberikan waktu untuk menyelesaikan proyek kreativitas yang harus memenuhi syarat yang telah didefinisikan. Syarat yang diberikan pada proyek mencakup kemampuan CT yang disediakan pada fitur dari Scratch [12]. Untuk proyek CodeCombat sesuai dengan The Computational Thinking in Mathematics and Science Taxonomy yang dicetuskan oleh Weintrop et al. [16]. Contoh pelaksanaan penjelasan dari fasilitator dapat dilihat pada Gambar 2 untuk materi Scratch dan Gambar 3 untuk materi CodeCombat.

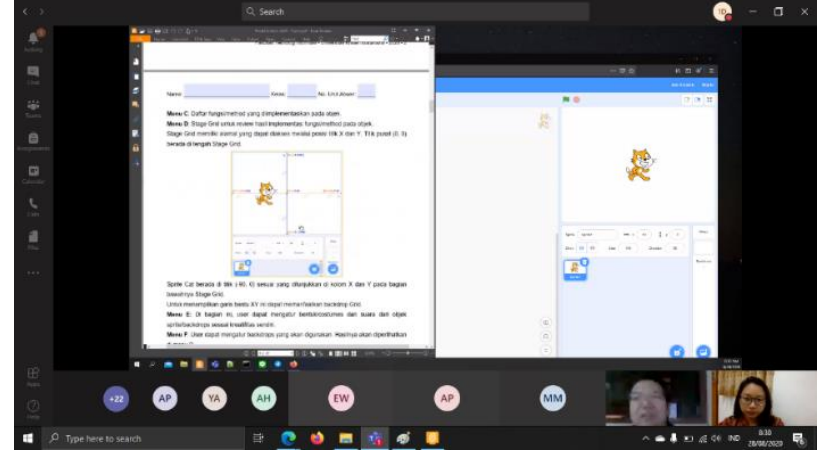

Gambar 2. Sesi penjelasan fasilitator untuk materi Scratch

Materi Scratch menggunakan pendekatan project-based learning. Proyek yang diberikan sudah memiliki beberapa syarat yang menjadi batasan bagi siswa dalam penyelesaiannya dan siswa juga tetap dapat berkreasi. Untuk proyek mandiri Scratch tersebut, siswa diharuskan membuat proyek terkait kesenian dan siswa juga didorong untuk menggunakan tema kebudayaan lokal, yaitu kebudayaan Sunda/Jawa Barat.

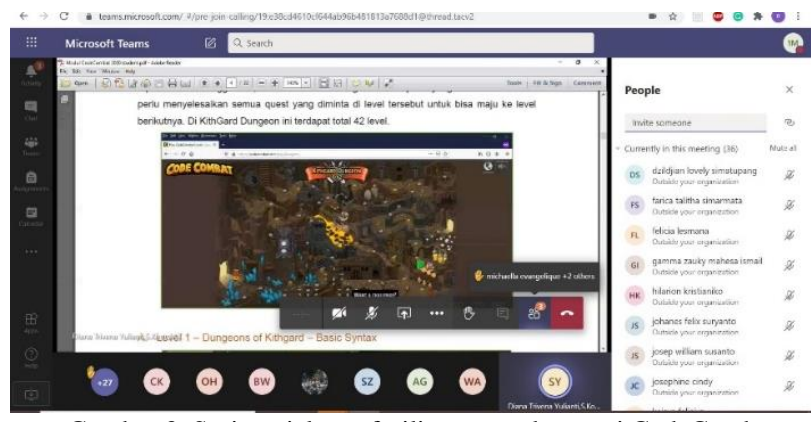

Gambar 3. Sesi penjelasan fasilitator untuk materi CodeCombat

Di akhir sesi pelaksanaan pengabdian kepada masyarakat ini, siswa diminta untuk mempresentasikan hasil kreativitas masing-masing. Contoh presentasi hasil kreativitas siswa dapat dilihat pada Gambar 4 untuk materi Scratch dan Gambar 5 untuk materi CodeCombat.

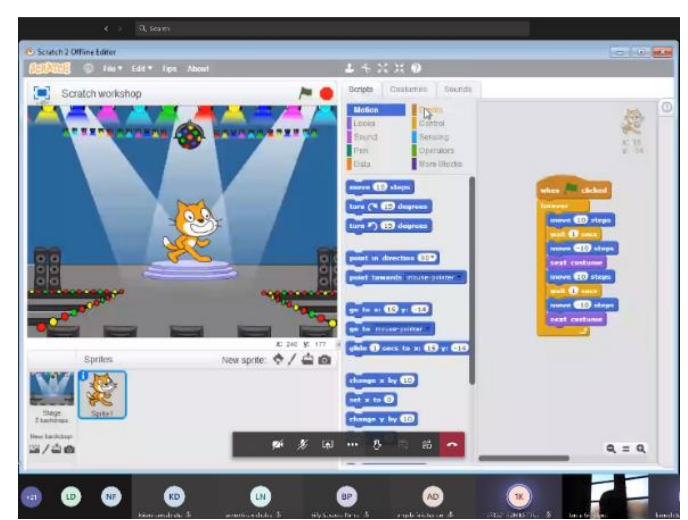

Gambar 4. Sesi presentasi hasil kreativitas siswa materi Scratch 
Pendekatan untuk materi CodeCombat adalah problembased learning. Kemampuan CT itu tidak sekedar membuat aplikasi komputer, tetapi juga harus terintegrasi dalam kurikulum pembelajaran [17]. Proyek mandiri CodeCombat kolaborasi dengan mapel Matematika berupa penyelesaian solusi dari setiap level game yang diminta. Siswa dapat berkreasi dalam menjawab karena solusi setiap level dapat diselesaikan dengan berbagai cara.

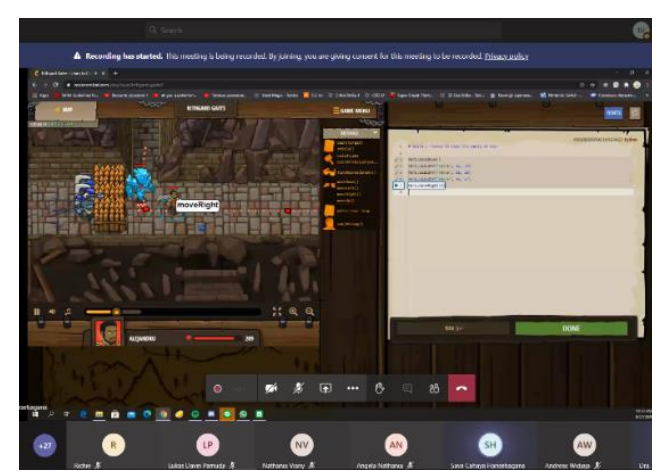

Gambar 5. Sesi presentasi hasil kreativitas siswa materi CodeCombat

Hasil kreativitas siswa ini dinilai oleh para fasilitator dan dipilih 3 karya terbaik untuk masing-masing kelasnya. Terdapat total 48 karya terbaik yang dipilih dari keseluruhan 16 kelas yang ada. Siswa yang memiliki karya terbaik ini diberikan apresiasi khusus dari FIT Maranatha. Hal ini diharapkan dapat mendorong siswa untuk semakin bersemangat dalam mengeksplorasi CT.

Di akhir pengabdian, terdapat survey yang dibagikan untuk diisi para siswa yang menjadi evaluasi bagi pelaksanaan pengabdian ini. Pertanyaan yang ada dalam survey dapat dilihat pada Tabel 2. Survey diukur menggunakan skala Likert dengan 4 pilihan, yaitu Sangat Setuju, Setuju, Tidak Setuju, dan Sangat Tidak Setuju.

TABEL II

Pertanyaan Evaluasi PelaksanaAn Kegiatan

\begin{tabular}{|c|l|}
\hline Kode & \multicolumn{1}{|c|}{ Pertanyaan } \\
\hline Q1 & Penyampaian materi mudah dimengerti \\
\hline Q2 & $\begin{array}{c}\text { Pemateri mampu berinteraksi dengan peserta dengan } \\
\text { baik }\end{array}$ \\
\hline Q3 & $\begin{array}{c}\text { Materi yang disampaikan dapat berguna bagi siswa } \\
\text { dalam proses pembelajaran di SMA }\end{array}$ \\
\hline Q4 & Pelayanan pemateri baik \\
\hline Q5 & Tujuan dari materi yang diberikan jelas \\
\hline Q6 & Pemateri menguasai materi yang diberikan \\
\hline Q7 & Kegiatan ini memenuhi harapan saya \\
\hline
\end{tabular}

Hasil survey yang dilakukan oleh siswa peserta pengabdian kepada masyarakat dapat dilihat pada Gambar 6.

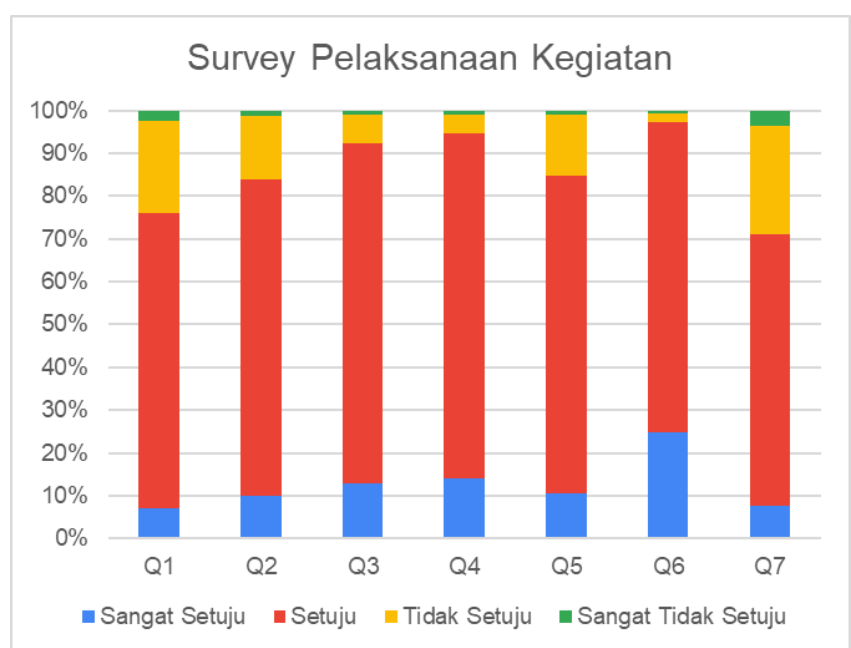

Gambar 6. Hasil survey pelaksanaan kegiatan

Secara rata-rata keseluruhan, $85.7 \%$ siswa setuju bahwa pelaksanaan kegiatan ini berjalan baik dan berguna bagi pembelajaran juga. Nilai setuju paling tinggi sejumlah 97.3\% diberikan untuk pertanyaan Q6 dimana artinya fasilitator menguasai materi yang diberikan. Pertanyaan Q3 dan Q5 yang terkait dengan isi materinya itu sendiri memiliki nilai setuju sejumlah $92.2 \%$ dan $84.7 \%$ secara berurutan. Hal ini menunjukkan respon siswa cukup baik dalam kegiatan ini dan harapannya materi ini benar-benar dapat menjadi titik awal bagi siswa untuk terus bereksplorasi terkait CT melalui pemrograman visual ini sehingga dapat mengembangkan kemampuan problem solving siswa dan membantu siswa dalam proses pembelajaran di sekolah maupun kehidupannya sehari-hari.

\section{KESIMPULAN}

Beberapa kesimpulan dari kegiatan pengabdian masyarakat terkait implementasi Computational Thinking melalui pemrograman visual yang telah diuraikan adalah:

a) Pelatihan implementasi CT melalui pemrograman visual pada siswa menengah atas berhasil dilaksanakan secara daring pada bulan Agustus 2020 oleh dosen dan mahasiswa FIT Maranatha dan diikuti oleh 473 orang siswa, 226 siswa berasal dari kelas X dan 247 siswa berasal dari kelas XI.

b) Pelatihan yang dilakukan memiliki tahapan persiapan, pemberian materi, dan sesi kreativitas siswa. Pelatihan juga diakhir dengan adanya evaluasi kegiatan dari para siswa.

c) Materi yang diberikan adalah Scratch untuk kelas $\mathrm{X}$ yang dikolaborasikan dengan mapel Kesenian dan menggunakan pendekatan project-based learning. Materi CodeCombat diberikan untuk kelas XI yang dikolaborasikan dengan mapel Matematika dan pendekatannya adalah problem-based learning. 
d) Proyek akhir yang diberikan menjadi sesi kreativitas siswa tetapi tetap memenuhi syarat proyek/masalah yang harus diselesaikan. Syarat-syarat ini didasarkan pada kemampuan CT yang ada.

e) Pelatihan ini diharapkan dapat menjadi titik awal bagi siswa untuk terus bereksplorasi terkait CT melalui pemrograman visual sehingga kemampuan problem solving dapat semakin terasah dan membantu siswa dalam kehidupan sehari-harinya.

\section{UCAPAN TERIMA KASIH}

Terima kasih kepada LPPM Universitas Kristen Maranatha yang telah mendukung dana untuk pelaksanaan pengabdian masyarakat ini. Terima kasih juga kepada SMA St. Angela Bandung yang mempercayakan kegiatan implementasi CT ini kepada FIT Maranatha.

\section{DAFTAR PUSTAKA}

[1] W. Kusumah, "Mata Pelajaran TIK Dihapus dalam Kurikulum 2013," 27 Februari 2018. [Online]. Available: https://www.kompasiana.com/wijayalabs/5a951874cf01b43e755ca38 2/matpel-tik-dihapus-dalam-kurikulum-2013. [Diakses 1 Agustus 2021].

[2] Pusat Kurikulum dan Pembelajaran, "Pedoman Implementasi Muatan/Mata Pelajaran Informatika Kurikulum 2013," Badan Penelitian dan Pengembangan Pusat Kurikulum dan Pembelajaran, Kementrian Pendidikan dan Kebudayaan, Jakarta, 2019.

[3] Cabinet Office, "Society 5.0," [Online]. Available: https://www8.cao.go.jp/cstp/english/society5_0/index.html. [Diakses 8 Agustus 2021].

[4] Computer Science Teachers Association (CSTA), "K-12 Computer Science Standards," Association for Computing Machinery, 2017.

[5] V. Dagiene and G. Stupuriene, "Informatics Concepts and Computational Thinking in K-12 Education: A Lithuanian Perspective," Journal of Information Processing, vol. 24, no. 4, pp. 732-739, July 2016.

[6] J. A. Q. Figueiredo, "How to Improve Computational Thinking: a Case Study," Education in the Knowledge Society (EKS), vol. 18, no. 4, pp. 35-51, 2017.

[7] Penulis Sekolah Penggerak, "Program Sekolah Penggerak," 10 Februari 2021. [Online]. Available: https://sekolah.penggerak.kemdikbud.go.id/programsekolahpenggera k/2021/02/10/tingkatkan-mutu-pendidikan-daerah-nadiemluncurkan-program-sekolah-penggerak-3/. [Diakses 1 Agustus 2021].

[8] M. Ayub, M. C. Wijanto, W. F. Senjaya, O. Karnalim, T. Kandaga, T. Witono, D. Edi, S. F. Sujadi, D. S. Kartawihardja, S. Santoso and T. Gantini, "Edukasi Berpikir Komputasional melalui Pelatihan Guru dan Tantangan Bebras untuk Siswa di Bandung pada tahun 2016," dalam Sendimas, Bandung, Indonesia, 2017.

[9] M. C. Wijanto, M. Ayub, W. F. Senjaya, H. Toba, S. Santoso, O. Karnalim, T. Kandaga, B. S. Panca, S. F. Sujadi, D. Edi and A. Adelia, "Evaluasi Pelaksanaan Tantangan Bebras untuk Siswa di Biro Universitas Kristen Maranatha pada tahun 2017 - 2018 untuk Edukasi Computational Thinking," dalam Sendimas, Semarang, Indonesia, 2019.

[10] M. C. Wijanto, O. Karnalim, M. Ayub, H. Toba and R. Tan, "Transitioning from Offline to Online Learning: Issues from
Computing Student Perspective," dalam 2021 IEEE Global Engineering Education Conference (EDUCON), Vienna, Austria, 2021.

[11] O. Karnalim and M. C. Wijanto, "Transitioning to Online Learning for Indonesian High School Students: Challenges and Possible Solutions," dalam 2021 International Conference on Advanced Learning Technologies (ICALT), Online, 2021.

[12] L. Zhang and J. Nouri, "A systematic review of learning computational thinking through Scratch in K-9," Computers \& Education, vol. 141, November 2019.

[13] L. R. Milne, "Blocks4All: making block programming languages accessible for blind children," ACM SIGACCESS Accessibility and Computing, no. 117, pp. 26-29, Januari 2017.

[14] Scratch Team, "Scratch - About," [Online]. Available: https://scratch.mit.edu/about. [Diakses 10 Agustus 2021].

[15] CodeCombat Team, "About CodeCombat," CodeCombat, 2021. [Online]. Available: https://codecombat.com/about. [Diakses 7 Agustus 2021].

[16] D. Weintrop, E. Beheshti, M. Horn, K. Orton, K. Jona, L. Trouille and U. Wilensky, "Defining Computational Thinking for Mathematics and Science Classrooms," Journal of Science Education and Technology, vol. 25, pp. 127-147, 2016.

[17] V. Kite, S. Park and E. Wiebe, "The Code-Centric Nature of Computational Thinking Education: A Review of Trends and Issues in Computational Thinking Education Research," SAGE Open, vol. 11, no. 2, pp. 1-17, April 2021. 